\title{
Plasma Pancreatic Glucagon Response to Blood Glucose in Experimental Pancreatolithiasis in Dogs
}

\author{
N.Okumura, T. Hayakawa, A. Sakakibara, A. Noda and T. Kondo \\ The Second Department of Internal Medicine, Nagoya University School of Medicine, Nagoya, Japan
}

Summary. In an attempt to study pancreatic A cell function at an early stage of pancreatic diabetes secondary to chronic pancreatitis, both intravenous glucose $(0.5 \mathrm{~g} / \mathrm{kg})$ and insulin $(0.5 \mathrm{U} / \mathrm{kg})$ tolerance tests were performed on seven dogs with pancreatolithiasis and seven normal control dogs. Experimental pancreatolithiasis was produced 12 months after incomplete ligation of the greater pancreatic duct. Impaired glucose tolerance and reduced plasma insulin response to an intravenous glucose load were observed in the calcified group. Pancreatic release of glucagon to insulin-induced hypogly- caemia was diminished, but suppressive response of the hormone to glucose-induced hyperglycaemia was well preserved. These data suggest that the A cell response to hypoglycaemia may be impaired earlier than that to hyperglycaemia in pancreatic diabetes secondary to pancreatolithiasis.

Key words: Experimental pancreatolithiasis, pancreatic diabetes, chronic pancreatitis, immunoreactive glucagon, intravenous glucose tolerance test, intravenous insulin tolerance test.
Pancreatic lithiasis is a common late complication of long-standing chronic pancreatitis. Pancreatic diabetes occurs more often in patients with calcified than those with non-calcified pancreatitis $[1,2]$. Little is known about pancreatic endocrine function at an early stage of diabetes associated with pancreatic lithiasis [3].

In the present study an attempt was made to investigate the response of plasma pancreatic glucagon to glucose and insulin in dogs with pancreatolithiasis.

\section{Materials and Methods}

\section{Animal Preparation}

The 14 dogs were divided into two weight-matched groups; $18 . \pm 3 \mathrm{~kg}$ (range $14-24 \mathrm{~kg}$ ) in the control group and $18 \pm 4 \mathrm{~kg}$ (range $14-25 \mathrm{~kg}$ ) in other group. Details of the operative procedures for producing experimental pancreatolithiasis have been reported previously $[4,5]$. The greater pancreatic duct was incompletely ligated with stainless steel wire. The lesser duct was ligated and then cut separately. The dogs were fed commercial dog food and the mean weight was not significantly changed during the 12 months. Pancreatic calculi were identified by autopsy 12 months after the operation. The gland was indurated, nodular and atrophic. Acinar alterations including atrophy, disorganization and interlobular replacement of fibrous connective tissue were present in moderate degree. In the control dogs neither calculi nor histological abnormalities were found at autopsy.

\section{Protocols of Pancreatic Endocrine Function Tests}

Pancreatic endocrine function was studied by intravenous injection of glucose or insulin in the conscious state. In seven dogs with pancreatic calcification, the test was carried out 12 months after the surgical intervention.

Intravenous Glucose Tolerance Test: A butterfly needle was inserted into an antecubital vein, and glucose $(0.5 \mathrm{~g} / \mathrm{kg})$ infused for $2 \mathrm{~min}$ using a peristaltic pump (Gilson Minipuls Pump HP-1, Villiers-le-Bel, France). Blood was taken through the butterfly needle in the opposite antecubital vein before and after glucose infusion at regular intervals for $60 \mathrm{~min}$.

Intravenous Insulin Tolerance Test: Highly purified porcine insulin (Actrapid MC, Novo Research Institute, Denmark) in a dose of $0.5 \mathrm{U} / \mathrm{kg}$ in $1 \mathrm{ml}$ of $0.9 \% \mathrm{NaCl}$ solution was injected intravenously. Blood was drawn from the opposite antecubital vein before and after the rapid insulin injection at specified intervals for $120 \mathrm{~min}$.

Heparinized blood specimens were transferred immediately either into ice-chilled tubes for measurement of glucose and immunoreactive insulin (IRI) or into the tubes containing $\mathrm{Na}_{2}$ EDTA $(1.2 \mathrm{mg} / \mathrm{ml}$ of blood) and aprotinin $(1000 \mathrm{KIU} / \mathrm{ml}$ of blood, Trasylol, Bayer Pharmaceuticals, FRG) for measurement of immunoreactive glucagon (IRG). Plasma was stored at $-20^{\circ} \mathrm{C}$ until determination of both IRI and IRG.

\section{Assays and Statistical Analyses}

Methods for the determination of plasma glucose, IRI and IRG (using Unger antibody $30 \mathrm{~K}$ ) have been described previously [5]. The disappearance rate of glucose $(\mathrm{K})$ in plasma during the IV glucose toler- 
Table 1. Plasma glucose and immunoreactive insulin responses to intravenous administration of glucose

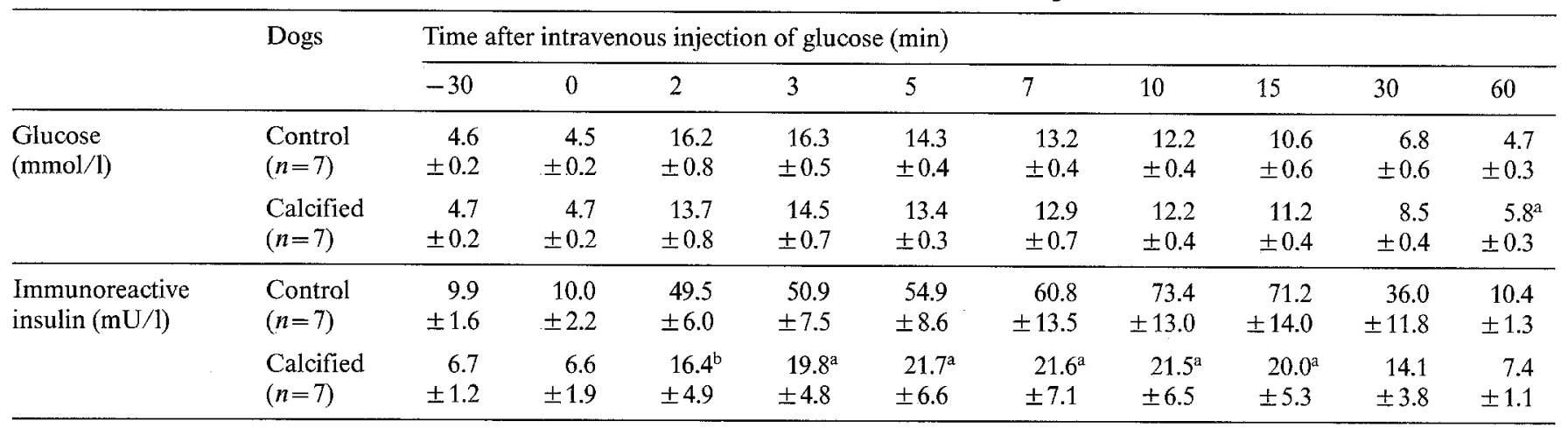

Values are expressed as mean $\pm \mathrm{SEM}$.

$(p<0.05)$ and

b. $(p<0.01)$ indicate a significant difference from control dogs (t-test)

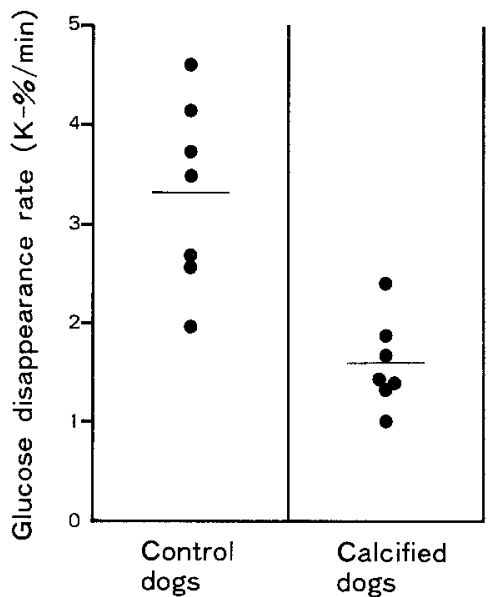

Fig. 1. Glucose disappearance rate $(K)$ in plasma of the control and calcified groups. Horizontal bars indicate mean values. $K$ values of the control and the calcified groups were significantly different $(p<0.01)$

ance test, an index of glucose tolerance, was calculated from the exponential curve, using the formula of Lundbaek [6].

For comparison within a group, Student's t-test for paired data was used. The t-test for two groups was employed for comparison between groups. A difference in the probability value of less than 0.05 was taken as the level of significance. Results are presented as mean \pm SEM

\section{Results}

\section{Plasma Glucose and IRI Responses to the IV Glucose Load}

Plasma glucose concentration between control and calcified groups was significantly different only at $60 \mathrm{~min}$ (Table 1). The mean disappearance rates of glucose (K) were $3.30 \pm 0.36$ and $1.58 \pm 0.17 \% / \mathrm{min}$ in the control and calcified groups, respectively. These values were significantly different $(p<0.01 ;$ Fig. 1$)$.

Fasting IRI levels between the two groups were not statistically different. The IRI response after the IV glu- cose load in the calcified group was lower than in the control group. Statistical differences were observed at 2-15 min (Table 1).

\section{Plasma IRG Response to the IV Glucose Load}

The IRG declined significantly from the basal value of $165 \pm 17 \mathrm{pg} / \mathrm{ml}$ to a nadir of $119 \pm 15 \mathrm{pg} / \mathrm{ml}$ in the control group and from $168 \pm 50$ to $115 \pm 35 \mathrm{pg} / \mathrm{ml}$ in the calcified group. The mean IRG decrements from the baseline were not significantly different between the two groups (Fig. 2).

\section{Plasma IRG Response to Insulin-Induced Hypoglycaemia}

Intravenous injection of insulin caused a significant fall in plasma glucose concentration in both groups. Plasma glucose declined from the basal value of $4.3 \pm$ $0.2 \mathrm{mmol} / 1$ to a nadir of $2.1 \pm 0.2 \mathrm{mmol} / \mathrm{l}$ in the control group and from $4.6 \pm 0.1$ to $1.7 \pm 0.2 \mathrm{mmol} / \mathrm{l}$ in the calcified group.

After insulin, mean levels of IRG rose significantly from a basal value of $172 \pm 12 \mathrm{pg} / \mathrm{ml}$ to a maximum of $377 \pm 72 \mathrm{pg} / \mathrm{ml}$ in the control group $(p<0.05)$. Although the degree of hypoglycaemia was similar to that of the control group, the IRG response to insulin-induced hypoglycaemia was not significantly different in the calcified group (basal value: $194 \pm 49 \mathrm{pg} / \mathrm{ml}$, maximum: $258 \pm 37$ pg/ml; Fig. 3).

\section{Discussion}

It has been reported that in overt diabetes secondary to chronic pancreatitis, suppression of pancreatic glucagon to an oral glucose load does not occur [1], and that release of the hormone is reduced after intravenous arginine [7] or during insulin-induced hypoglycaemia [8]. However, little is known about A cell function at an ear- 


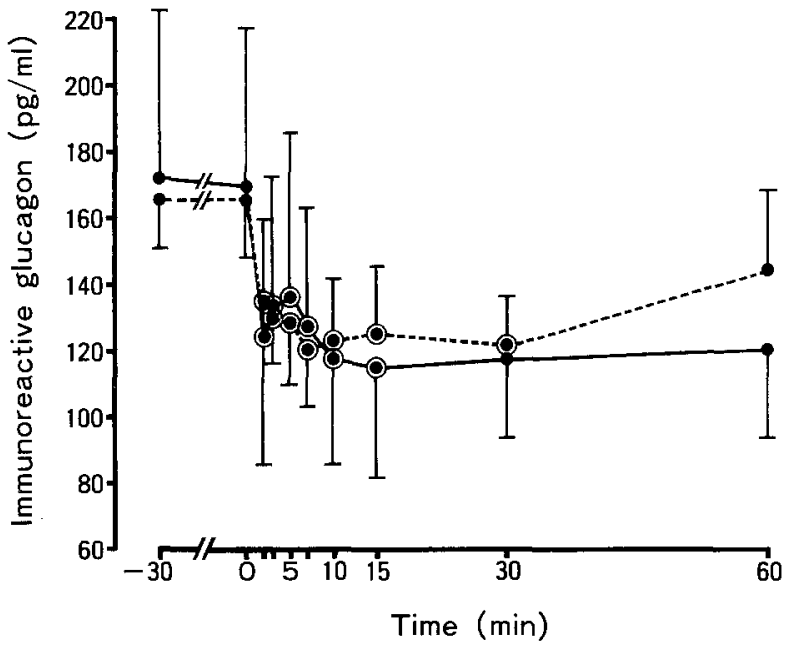

Fig. 2. Plasma glucagon response to intravenous administration of glucose in calcified $(\bullet \bullet)$ and control $(\bullet-\cdots)$ dogs. Vertical bars indicate standard errors. Circled symbols denote a significant difference from basal value $(p<0.05)$
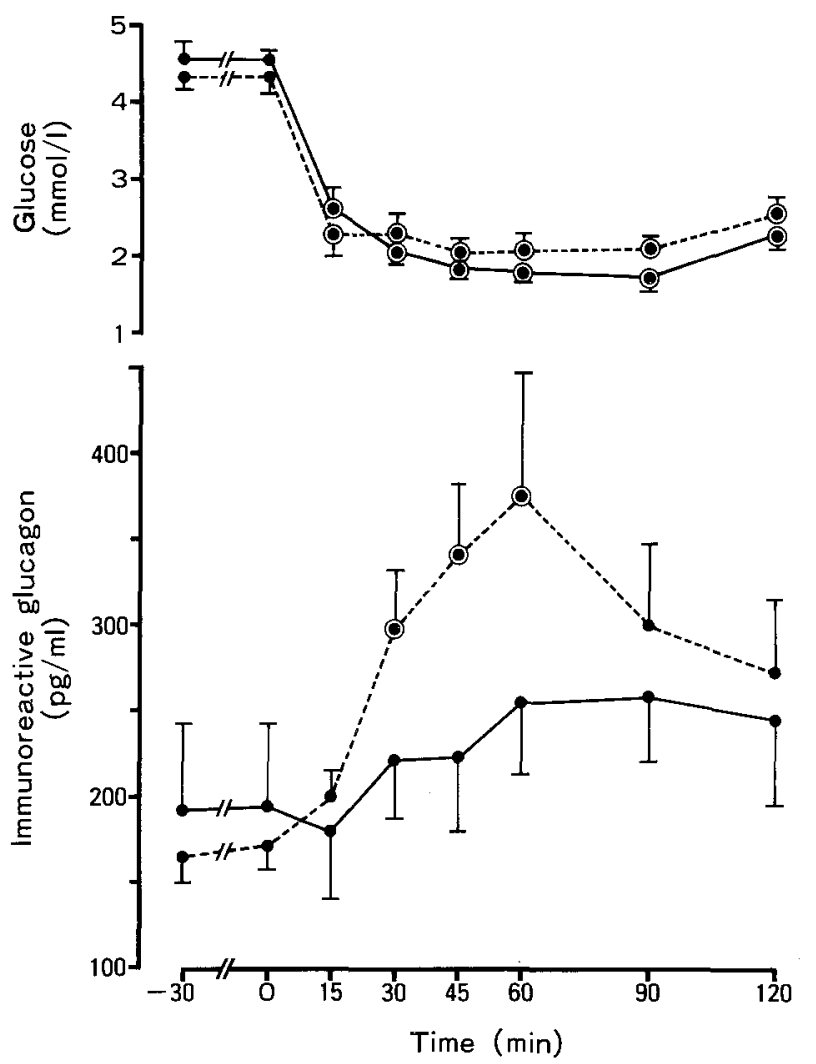

Fig.3. Plasma glucose and glucagon responses to intravenous administration of insulin in calcified $(\bullet \bullet)$ and control $(\bullet---\bullet)$ dogs. Vertical bars indicate standard errors. Circled symbols denote a significant difference from basal value $(p<0.05)$

ly stage of diabetes secondary to chronic pancreatitis, especially that due to pancreatolithiasis.

In the present study, two stimuli (glucose-induced hyperglycaemia and insulin-induced hypoglycaemia) were employed to assess pancreatic $A$ cell function. The response of plasma IRG to intravenous administration of glucose or insulin is independent of gut hormones. The secretory capacity of the A cell in the pancreas was assessed by insulin-induced hypoglycaemia instead of an arginine load. Arginine stimulates secretion of gastric glucagon which is indistinguishable from pancreatic glucagon in normal dogs [9], depancreatized dogs [10-12], and isolated perfused dog stomach [13]; in contrast gastric glucagon is not released during insulininduced hypoglycaemia in either normal [9] or depancreatized dogs [10]. Matsuyama et al. [10] reported that insulin-induced hypoglycaemia did not raise the plasma concentration of IRG in depancreatized dogs, but it was raised significantly in normal dogs. We confirmed their results in a preliminary experiment. Therefore, the IRG response to hypoglycaemia requires the presence of the pancreas and insulin-induced hypoglycaemia is a more specific stimulus to pancreatic glucagon secretion. In the present study, a significant rise of IRG to insulininduced hypoglycaemia was observed in the control dogs but not in the dogs with pancreatolithiasis.

Kirk et al. [14] reported plasma insulin and glucagon responses to a $25 \mathrm{~g}$ intravenous glucose infusion among non-diabetic first-degree relatives of diabetic and normal subjects. According to them the glucagon level was unchanged in first-degree relatives with diminished first-phase insulin release even in the presence of hyperglycaemia, while suppressed to a significant degree in the other relatives and control subjects. They concluded that their data provided evidence for an A cell abnormality of genetic diabetes. On the contrary, Aronoff et al. [15] failed to demonstrate an abnormal glucagon response to intravenous glucose infusion in prediabetic Pima Indians who had had two or more oral glucose tolerance tests during the past 10 years which were normal and whose parents both had diabetes. In the present study, hyperglycaemic suppression of IRG was observed in dogs with pancreatolithiasis as well as in control dogs, although both glucose tolerance and B cell function were impaired only in the former group. This is compatible with the results observed in man by Aronoff et al. [15]. The A cell response to an intravenous glucose load seems to be independent of B cell function in an early stage of pancreatic diabetes.

Ultrastructural changes of A and B cells appeared 3-6 months after duct ligation in dogs with pancreatolithiasis. Using an immunoperoxidase staining technique, the staining intensity was evaluated in the A cell for pancreatic glucagon and B cell for insulin in some of the dogs studied in this experiment. The intensity became weaker in the A as well as B cells in the pancreatolithiasis dogs when compared with the control dogs (unpublished data).

In conclusion, in a prediabetic state in experimental pancreatolithiasis pancreatic release of glucagon to insulin-induced hypoglycaemia was much impaired, but suppression of the hormone in response to hyperglycaemia occurred in much the same manner as in control dogs. Dysfunction of the A cell to hypoglycaemia seems 
to precede that to hyperglycaemia in diabetes secondary to pancreatolithiasis.

Acknowledgements. This project was supported in part by a research grant of Intractable Pancreatic Disease from Intractable Division, Public Health Bureau, Welfare Ministry in Japan.

\section{References}

1. Hayakawa T, Noda A, Suzuki T, Aoki I, Inoue J, Horiguchi Y, Kamiya N, Takayama T, Nakamura M, Okumura N (1977) Plasma pancreatic glucagon and insulin responses to oral glucose load in chronic pancreatitis. Jpn J Gastroenterol 74: 130-137

2. Bank S, Marks IN, Vinik AI (1975) Clinical and hormonal aspects of pancreatic diabetes. Am J Gastroenterol 64: 13-22

3. Okumura N, Hayakawa T, Noda A, Kondo T, Sakakibara A, Katada N, Satake T, Suzuki T, Kato K (1982) Follow-up of the endocrine and exocrine functions of the pancreas in three patients with chronic alcoholic pancreatitis in progression of pancreatic calcification. J Jpn Soc Int Med 71: 340-349

4. Takayama T (1979) Pathophysiological study of experimental pancreatolithiasis in the dog. Jpn J Gastroenterol 76: 1325-1336

5. Okumura N, Sakakibara A, Hayakawa T, Noda A (1982) Pancreatic endocrine function in experimental pancreatolithiasis in dogs. Am J Gastroenterol 77: 392-396

6. Lundbaek K (1962) Intravenous glucose tolerance as a tool in definition and diagnosis of diabetes mellitus. Br Med J I: 1507-1513

7. Assan R, Tiengo A (1973) Comparaison des sécrétions de glucagon dans les diabètes sucrés avec ou sans pancréatopathie organique acquise. Pathol Biol 21: 17-25

8. Persson I, Gyntelberg F, Heading LG, Boss-Nielsen J (1971) Pancreatic-glucagon-like immunoreactivity after intravenous insulin in normals and chronic-pancreatitis patients. Acta Endocrinol 67 : $401-404$

9. Munõz-Barragan L, Blazquez E, Patton GS, Dobbs RE, Unger RH (1976) Gastric A-cell function in normal dogs. Am J Physiol 231: 1057-1061

10. Matsuyama T, Tanaka R, Shima K, Nonaka K, Tarui S (1978) Lack of gastrointestinal glucagon response to hypoglycaemia in depancreatized dogs. Diabetologia 15: 471-474

11. Blazquez E, Munõz-Barragan L, Patton GS, Dobbs RE, Unger RH (1976) Gastric A-cell function in insulin-deprived depancreatized dogs. Endocrinology 99: 1182-1188

12. Muller WA, Girardier L, Seydoux J, Berger M, Renold AE, Vranic M (1978) Extrapancreatic glucagon and glucagon-like immunoreactivity in depancreatized dogs. J Clin Invest 62: 124-132

13. Lefèbvre PJ, Luyckx AS (1977) Factors controlling gastric-glucagon release. J Clin-Invest 59: 716-722

14. Kirk RD, Dunn PJ, Smith JR, Beaven DW, Donald RA (1975) Abnormal pancreatic alpha-cell function in first-degree relatives of known diabetics. J Clin Endocrinol Metab 40:913-916

15. Aronoff SL, Benett PH, Unger RH (1977) Immunoreactive glucagon responses to intravenous glucose in prediabetes and diabetes among Pima Indians and normal Caucasians. J Clin Endocrinol Metab 44: 968-972

Received: 9 November 1982

and in revised form: 6 June 1983

Dr. N.Okumura

The Second Department of Internal Medicine

Nagoya University School of Medicine

65 Tsuruma-cho

Showa-ku

Nagoya 466, Japan 